\title{
Early-Age Strength and Workability of Basalt Fiber Reinforced- Concrete Made with Recycled Aggregates - A Pilot Study
}

\author{
Shahrukh Shoaib $^{1}$, Hilal El-Hassan ${ }^{1}$, Bilal El-Ariss ${ }^{1}$, Tamer El Maaddawy ${ }^{1}$ \\ ${ }^{1}$ UAE University \\ P.O. Box 15551, Al Ain, United Arab Emirates \\ 201890010@uaeu.ac.ae; helhassan@uaeu.ac.ae; bilal.elariss@uaeu.ac.ae; tamer.maaddawy@uaeu.ac.ae
}

\begin{abstract}
This research presents the combined effect of replacing natural aggregates by recycled concrete aggregates (RCA) and incorporating basalt fibers on the workability, 7-day compressive strength, and 7-day splitting tensile strength of concrete mixes. Three target design compressive strengths were used (30,45, and $60 \mathrm{MPa})$. Untreated RCA were used in addition to two types of basalt fibers at volume fractions ranging from 0 to $3 \%$. The basalt fiber types used in this work had lengths of 20 and 43 mm. Locally available desert dune sand was utilized in concrete mixes as a sustainable replacement to conventional crushed fine aggregates. The experimental results showed that the incorporation of basalt fibers resulted in a significant decrease in the workability of fresh concrete. The retention of 7day compressive strength in basalt fiber-reinforced RCA concrete was superior when the design strength was $30 \mathrm{MPa}$ rather than 45 and $60 \mathrm{MPa}$. The 7-day splitting tensile strength of RCA-based concrete was effectively restored upon the addition of basalt fibers. It exceeded that of the control mixes with higher basalt fiber volume fractions and $43 \mathrm{~mm}$-long basalt fibers.
\end{abstract}

Keywords: Basalt fiber, recycled concrete aggregates, dune sand, sustainability, compressive strength, splitting tensile strength

\section{Introduction}

The rapid growth of the world's population demands the construction of more infrastructure. In the process, more concrete is needed, rendering it one of the most extensively used materials in the world [1]. Coarse aggregates, a major constituent in concrete, are extracted from natural non-renewable resources. With the increasing need for concrete, more coarse aggregates are being used, instigating the depletion of natural aggregate resource. It is therefore necessary to find an alternative material that can replace natural coarse aggregates as the main filler in concrete with limited to no effect on the concrete's performance.

Generally, after its service life, a concrete structure is demolished, thus producing an excessive amount of waste, i.e., construction and demolition waste (CDW). Such waste is typically disposed of in landfills. While it is considered a steadfast means of resolving the problem of waste management, it has hazardous environmental effects through leeching into the ground [2]. Moreover, space to sort out CDW is becoming more limited in landfills [3]. As such, it is necessary to provide an alternative to properly manage $\mathrm{CDW}$.

The conversion of CDW into recycled concrete aggregates (RCA) has been suggested to relieve the stress on landfills by utilizing so-produced RCA as a replacement to natural aggregates (NA). The process serves to promote environmental sustainability [4]. Nonetheless, the use of RCA is limited to road construction as sub-base material, owing to its lower strength, higher water absorption and superior porosity compared to NA [5]. While some literature have focused on improving the properties of RCA by chemical or physical enhancement [6-7], others have incorporated additional components, including steel fibers [8-10]. However, there is limited literature available on the performance of concrete made with RCA and basalt fibers (BF). Feng et al. [11] studied the combined effect of RCA and basalt fibers on the performance of concrete. The basalt fibers of length $18 \mathrm{~mm}$ were added in range of $0-0.2 \%$, by volume, and the replacement ratio of RCA was $50 \%$. The experimental results showed that optimum contents of BF for cube compressive strength was $0.1 \%$, and for splitting tensile strength and elastic modulus, optimum value was $0.2 \%$. Further, Wang et al. [12] studied the combined influence of basalt fibers and nano-silica on the properties of concrete made with 50 and 100\% RCA. Basalt fibers of $32 \mathrm{~mm}$ length were added in range of $0-3 \mathrm{~kg} / \mathrm{m}^{3}$. The experimental results showed that for $100 \% \mathrm{RCA}$ concrete, flexural strength 
was maximum at BF contents of $2 \mathrm{~kg} / \mathrm{m}^{3}$. Clearly, there is a need for more research on the effect of RCA and basalt fibers on structural concrete.

Accordingly, this research article is a pilot study that aims to examine the early-age strength and workability properties of concrete made with dune sand, RCA and BF having different lengths. Natural coarse aggregates were replaced by $100 \%$ RCA, which was provided in an untreated shape from a local recycling plant. Locally available dune sand was used as sustainable fine aggregates to promote environmental sustainability. Concrete mixes were designed to attain compressive strengths of 30,45, and $60 \mathrm{MPa}$. The coupled effect of $100 \% \mathrm{RCA}$ and up to $3 \% \mathrm{BF}$, by volume, on the workability, 7-day compressive strength, and 7-day splitting tensile strength was investigated.

\section{Materials and Methods}

\subsection{Materials}

ASTM Type-I cement, NA, untreated RCA, dune sand, and tap water were used for concrete mix preparation and curing of specimens. RCA were obtained from a local recycling plant with nominal maximum size (NMS) of $25 \mathrm{~mm}$, dry rodded density of $1563 \mathrm{~kg} / \mathrm{m}^{3}$, water absorption of $6.62 \%$, Los Angeles abrasion of $32.6 \%$, specific gravity of 2.63 , fineness modulus of 7.74, soundness of $2.7 \%$, and surface area of $2.5 \mathrm{~cm}^{2} / \mathrm{g}$. In comparison, NA were in the form of dolomitic limestone with NMS of $20 \mathrm{~mm}$, dry rodded density of $1635 \mathrm{~kg} / \mathrm{m}^{3}$, water absorption of $0.22 \%$, Los Angeles abrasion of $16.0 \%$, specific gravity of 2.82, fineness modulus of 6.82 , soundness of $1.2 \%$ and surface area of $2.49 \mathrm{~cm}^{2} / \mathrm{g}$. Dune sand consists of very fine particles, ranging between 300 to 600 microns, with a unit weight of $1663 \mathrm{~kg} / \mathrm{m}^{3}$, water absorption of $19.92 \%$, specific gravity of 2.77 , and fineness modulus of 2.24 . Both coarse aggregates, RCA and NA, were used in saturated surface dry (SSD) condition to account for water absorption. Two types of basalt fibers were used with mean lengths $\left(l_{f}\right)$ of 20 and $43 \mathrm{~mm}$ and aspect ratios $\left(l_{f} / d_{f}\right)$ of 28 and 61, respectively. Each type of BF had a mean diameter $\left(\mathrm{d}_{\mathrm{f}}\right)$ of $0.7 \mathrm{~mm}$, tensile strength of $1100 \mathrm{MPa}$, specific gravity of 1.9, and Young's modulus of $60 \mathrm{GPa}$. The two types of basalt fibers are shown in Fig. 1.

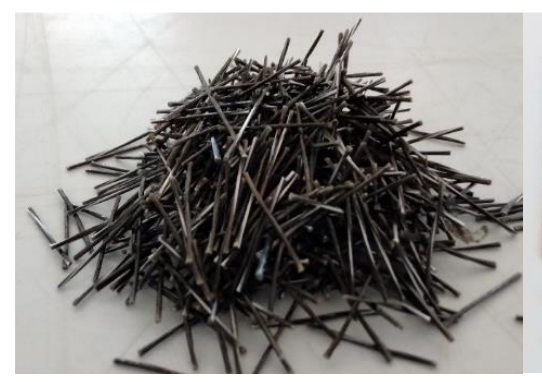

(a)

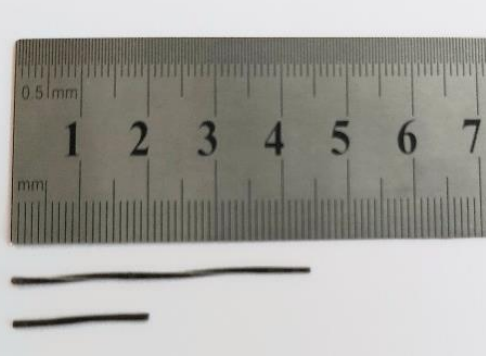

(b)

Fig. 1: (a) Physical appearance of basalt fibers and (b) length of basalt fibers

\subsection{Mix Proportioning}

Concrete mixes were prepared as per provisions of BS EN 206 [13], having target 28-day cube compressive strengths of 30, 45 and $60 \mathrm{MPa}$. Samples made with 100\% natural aggregates served as a benchmark. Table 1 shows the constituents of each concrete mix. They were labelled as $x$ RyBFz/n, where $x$ represents target compressive strength (in $\mathrm{MPa}), \mathrm{y}$ is percentage of RCA (\%), $\mathrm{z}$ is volume fraction of basalt fibers (\%), and $\mathrm{n}$ represents the length of basalt fiber (in $\mathrm{mm}$ ). For instance, 30R100BF0.5/20 represents a $30 \mathrm{MPa}$-concrete made with $100 \%$ recycled concrete aggregates, and $0.5 \%$ volume fraction of $20 \mathrm{~mm}$-long basalt fibers.

\subsection{Sample Preparation}

Concrete mixes were prepared in the laboratory at $24 \pm 2{ }^{\circ} \mathrm{C}$ and $50 \pm 5 \%$ relative humidity. Dry components, including cement and fine and SSD-coarse aggregates were mixed in a concrete mixer for 3 minutes. Water was then 
added and mixed with the dry components for another 3 minutes to ensure uniformity. Basalt fibers were incorporated into the mix at the end of the mixing period to avoid damaging the fibers. Fresh concrete was then cast into $100 \mathrm{~mm} \times 200 \mathrm{~mm}$ cylinders and $100 \mathrm{~mm}$ cubes and compacted using a vibrating table. The specimens were covered with plastic sheet for 24 hours, demoulded after one day and placed in water tank for curing until testing at an age of 7 days. Three specimens were prepared for each test.

Table 1: Mix proportions of concrete mixes with different basalt fiber contents

\begin{tabular}{|c|c|c|c|c|c|c|c|}
\hline Mix Design & $\begin{array}{l}\text { Cement } \\
\left(\mathrm{kg} / \mathrm{m}^{3}\right)\end{array}$ & $\begin{array}{c}\text { Sand } \\
\left(\mathrm{kg} / \mathrm{m}^{3}\right)\end{array}$ & $\begin{array}{c}\mathrm{NA} \\
\left(\mathrm{kg} / \mathrm{m}^{3}\right)\end{array}$ & $\begin{array}{c}\text { RCA } \\
\left(\mathrm{kg} / \mathrm{m}^{3}\right)\end{array}$ & $\begin{array}{c}\text { Water } \\
\left(\mathrm{kg} / \mathrm{m}^{3}\right)\end{array}$ & $\begin{array}{c}\text { Superplasticizer } \\
\left(\mathrm{kg} / \mathrm{m}^{3}\right)\end{array}$ & $\begin{array}{c}\mathrm{BF} \\
\left(\mathrm{kg} / \mathrm{m}^{3}\right)\end{array}$ \\
\hline 30R0BF0 & 470 & 570 & 1130 & 0 & 230 & 0.00 & 0.0 \\
\hline 30R100BF0 & 470 & 570 & 0 & 1130 & 230 & 0.00 & 0.0 \\
\hline 30R100BF0.5/43 & 470 & 570 & 0 & 1130 & 230 & 0.00 & 10.5 \\
\hline 30R100F1/43 & 470 & 570 & 0 & 1130 & 230 & 0.00 & 21.0 \\
\hline 30R100F1.5/43 & 470 & 570 & 0 & 1130 & 230 & 0.00 & 31.5 \\
\hline 30R100BF0.5/20 & 470 & 570 & 0 & 1130 & 230 & 0.00 & 10.5 \\
\hline 30R100F1/20 & 470 & 570 & 0 & 1130 & 230 & 0.00 & 21.0 \\
\hline 30R100F1.5/20 & 470 & 570 & 0 & 1130 & 230 & 0.00 & 31.5 \\
\hline $30 \mathrm{R} 100 \mathrm{~F} 2 / 20$ & 470 & 570 & 0 & 1130 & 230 & 0.00 & 42.0 \\
\hline 30R100F3/20 & 470 & 570 & 0 & 1130 & 230 & 0.00 & 63.0 \\
\hline 45R0BF0 & 567 & 543 & 1100 & 0 & 216 & 0.62 & 0.0 \\
\hline 45R100BF0 & 567 & 543 & 0 & 1100 & 216 & 0.62 & 0.0 \\
\hline 45R100BF0.5/43 & 567 & 543 & 0 & 1100 & 216 & 0.62 & 10.5 \\
\hline 45R100F1/43 & 567 & 543 & 0 & 1100 & 216 & 0.62 & 21.0 \\
\hline 45R100BF1.5/43 & 567 & 543 & 0 & 1100 & 216 & 0.62 & 31.5 \\
\hline 45R100BF0.5/20 & 567 & 543 & 0 & 1100 & 216 & 0.62 & 10.5 \\
\hline 45R100F1/20 & 567 & 543 & 0 & 1100 & 216 & 0.62 & 21.0 \\
\hline 45R100F1.5/20 & 567 & 543 & 0 & 1100 & 216 & 0.62 & 31.5 \\
\hline 45R100F $2 / 20$ & 567 & 543 & 0 & 1100 & 216 & 0.62 & 42.0 \\
\hline 45R100F3/20 & 567 & 543 & 0 & 1100 & 216 & 0.62 & 63.0 \\
\hline 60R0BF0 & 617 & 513 & 1079 & 0 & 216 & 0.92 & 0.0 \\
\hline 60R100BF0 & 617 & 513 & 0 & 1079 & 216 & 0.92 & 0.0 \\
\hline 60R100BF0.5/43 & 617 & 513 & 0 & 1079 & 216 & 0.92 & 10.5 \\
\hline 60R100F1/43 & 617 & 513 & 0 & 1079 & 216 & 0.92 & 21.0 \\
\hline 60R100BF1.5/43 & 617 & 513 & 0 & 1079 & 216 & 0.92 & 31.5 \\
\hline 60R100BF0.5/20 & 617 & 513 & 0 & 1079 & 216 & 0.92 & 10.5 \\
\hline 60R100F1/20 & 617 & 513 & 0 & 1079 & 216 & 0.92 & 21.0 \\
\hline 60R100F1.5/20 & 617 & 513 & 0 & 1079 & 216 & 0.92 & 31.5 \\
\hline 60R100F2/20 & 617 & 513 & 0 & 1079 & 216 & 0.92 & 42.0 \\
\hline 60R100F3/20 & 617 & 513 & 0 & 1079 & 216 & 0.92 & 63.0 \\
\hline
\end{tabular}

\subsection{Performance Evaluation}

The experimental program consisted of casting more than 150 specimens to study workability, compressive strength, and splitting tensile strength of different concrete mixes. The provisions of ASTM C143 [14] were followed to determine slump of fresh concrete mixes. Compressive and splitting tensile strength tests were performed on $100 \mathrm{~mm}$ cubes and $100 \mathrm{x}$ $200 \mathrm{~mm}$ cylinders at 7 days in accordance with BS EN 12390-3 [15] and ASTM C496 [16], respectively. The load was applied at rate of 7 and $1 \mathrm{kN} / \mathrm{s}$ using compression testing machine of $2000 \mathrm{kN}$ capacity, respectively. The average result of the three replicate specimens was used in the analysis. 


\section{Results and Discussion}

\subsection{Slump}

The workability of concrete was characterized by its slump. It is worth noting that the mixture proportions of the benchmark/control concrete mix, i.e., cement, aggregates, and water contents, were not changed throughout the program. Fig. 2 demonstrates the workability of different concrete mixes. The mixes labelled 'CON' and ' $0 \%$ ' in this and all subsequent figures refer to the control mix having 100\% NA and the concrete mix having a 100\% RCA and $0 \%$ basalt fiber volume fraction, respectively. The slump values of the control concrete mixes with target compressive strengths of 30, 45 and $60 \mathrm{MPa}$ were 155, 215, and $220 \mathrm{~mm}$, respectively. The replacement of coarse aggregates by $100 \%$ RCA resulted in negligible increase in the slump for 30 and $45 \mathrm{MPa}$ samples. However, for $60 \mathrm{MPa}-\mathrm{concrete}$, the workability decreased by $16 \%$, owing to the irregular particle shape of RCA [17]. The addition of $43 \mathrm{~mm}-\mathrm{long} \mathrm{BF}$ to the RCA-based mix at volume fractions of $0.5,1$ and $1.5 \%$ resulted in 16, 90, and $94 \%$ slump reduction compared to that of the control mix of $30 \mathrm{MPa}$. Moreover, the addition of up to 3\% volume fraction of $20 \mathrm{~mm}-$ long BF resulted in as much as $48 \%$ reduction in slump compared to $30 \mathrm{MPa}$-control concrete mix. Considering $45 \mathrm{MPa}$-concrete, the more 20 and $43 \mathrm{~mm} \mathrm{BF}$ were added to the mix, the higher the reduction in slump. In fact, at a fixed volume fraction of $1.5 \%$, a 93 and 35\% loss in workability was noted for 20 and $43 \mathrm{~mm}$ basalt fiber-reinforced RCA concrete. Clearly, longer fibers were more impactful. In case of $60 \mathrm{MPa}$ concrete, the addition of 20 and $43 \mathrm{~mm} \mathrm{BF}$ at volume fraction of 0.5-3\% and $0.5-1.5 \%$ led to a $28-73 \%$ and 66-98\% lesser slump compared to the control mix, respectively. Apparently, while the replacement of NA by RCA had a negligible effect on workability, the addition of basalt fiber was more influential, especially at higher volume fractions and with $43 \mathrm{~mm}$-long fibers.

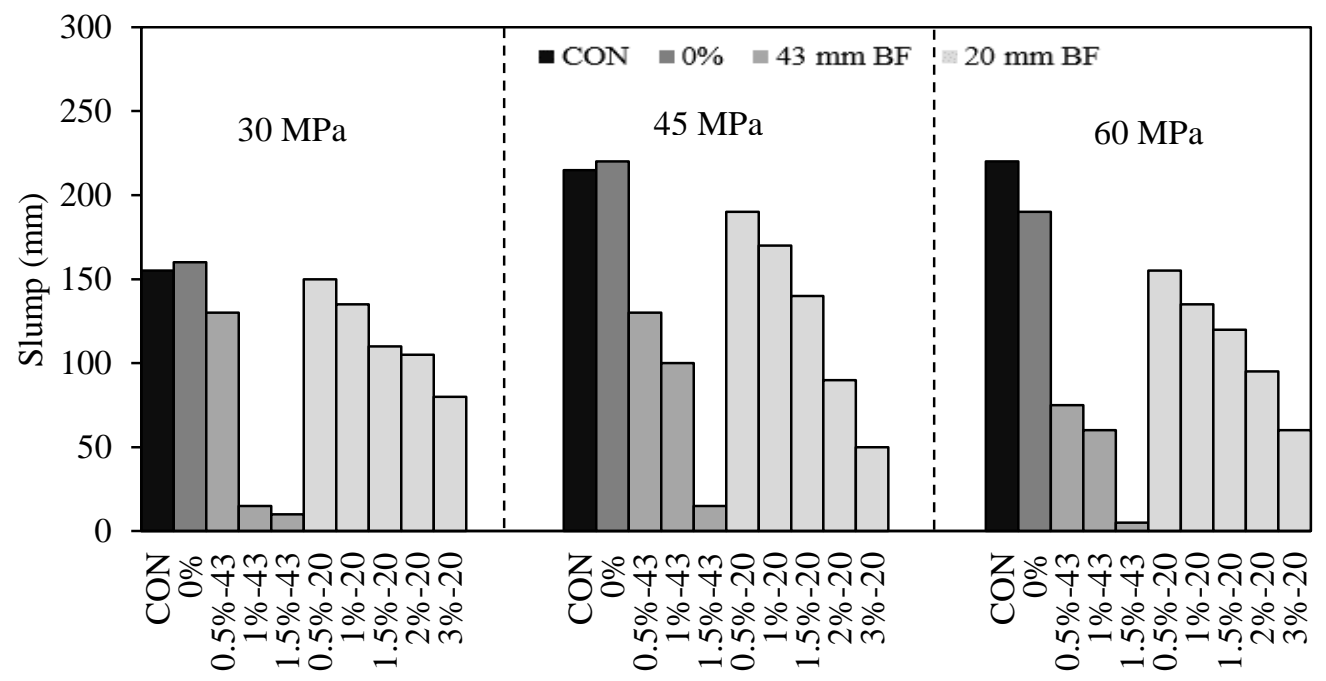

Fig. 2: Slump of concrete with different design strength, fiber lengths, and fiber volume fractions

\subsection{Compressive Strength}

The 7-day compressive strength of concrete made with different proportions of RCA and BF is shown in Fig. 3. Three replicate specimens per mix were used to obtain an average. The 7-day compressive strength of 30, 45, and 60 MPa control mixes was 33.4, 44.9, and $52.7 \mathrm{MPa}$, respectively. Upon the replacement of NA by $100 \%$ RCA, the compressive strength decreased by 47,47 , and 58\%. Clearly, the adverse effect of RCA replacement is intensified at higher design strengths.

Nevertheless, the compressive strength was enhanced with the addition of basalt fiber for 30, 45, and $60 \mathrm{MPa}$ RCA concrete mixes, as shown in Table 2. It should be noted that concrete with $1.5 \%$ volume fraction of $43 \mathrm{~mm} \mathrm{BF}$ were not tested, as samples could neither be cast nor compacted. In case of $30 \mathrm{MPa}$-concrete, the addition of $43 \mathrm{~mm}$ at volume fraction of 0.5 and $1 \%$ increased the compressive strength by 27 and $21 \%$, respectively, compared to concrete made with 
$100 \%$ RCA. Alternately, 0.5, 1, 1.5, 2, 3\% volume fractions of $20 \mathrm{~mm}$ BF resulted in 37, 10, 29, 25, and 17\% superior compressive strength to plain RCA-based concretes. While basalt fiber incorporation into 100\% RCA mixes is clearly beneficial, it is interesting to also report the strength retention compared to the control mix. Concrete made with $43 \mathrm{~mm}$ basalt fibers at volume fractions of $0.5-1 \%$ could retain between 62 and $65 \%$ of the compressive strength of the control mix. mix. Counterparts made with $20 \mathrm{~mm} \mathrm{BF}$ at volume fractions of $0.5,1,1.5,2$, and $3 \%$ resulted in retaining 70, 58, 66, 64, and 64, and $60 \%$. Apparently, both fibers could restore part of the lost compressive strength. Yet, $20 \mathrm{~mm}$ fibers seemed to be be slightly more effective.

Table 2: Comparison of compressive and splitting tensile strength of control and basalt fiber-reinforced concrete

\begin{tabular}{|c|c|c|c|c|c|c|}
\hline Mix Design & $\begin{array}{l}\text { Avg. } f_{\text {cu }} \\
(\mathrm{MPa})\end{array}$ & $\begin{array}{l}\text { Increase in } f_{\mathrm{cu}} \\
\text { compared to RCA } \\
\text { concrete }(\%)\end{array}$ & $\begin{array}{c}\text { Achieved } f_{\text {cu }} \text { of } \\
\text { BFRC as percent } \\
\text { of } \mathrm{NC}(\%)\end{array}$ & $\begin{array}{l}\text { Avg. } f_{t} \\
(\mathrm{MPa})\end{array}$ & $\begin{array}{c}\text { Increase in } f_{t} \\
\text { compared to RCA } \\
\text { concrete }(\%)\end{array}$ & $\begin{array}{l}\text { Achieved } f_{t} \text { of BFRC } \\
\text { as percent of } \mathrm{NC}(\%)\end{array}$ \\
\hline 30R0BF0 & 33.4 & - & - & 1.7 & - & - \\
\hline 30R100BF0 & 17.2 & - & - & 1.3 & - & - \\
\hline 30R100BF0.5/43 & 21.9 & 27 & 65 & 1.9 & 45 & 114 \\
\hline 30R100F1/43 & 20.8 & 21 & 62 & 2.4 & 86 & 147 \\
\hline 30R100BF0.5/20 & 23.5 & 37 & 70 & 1.8 & 36 & 107 \\
\hline 30R100F1/20 & 18.9 & 10 & 58 & 1.6 & 25 & 98 \\
\hline 30R100F1.5/20 & 22.2 & 29 & 66 & 1.9 & 42 & 112 \\
\hline 30R100F2/20 & 21.5 & 25 & 64 & 1.7 & 30 & 102 \\
\hline 30R100F3/20 & 20.1 & 17 & 60 & 1.9 & 48 & 117 \\
\hline 45R0BF0 & 44.9 & - & - & 2.3 & - & - \\
\hline 45R100BF0 & 23.9 & - & - & 1.5 & - & - \\
\hline 45R100BF0.5/43 & 27.2 & 14 & 61 & 2.2 & 47 & 95 \\
\hline 45R100F1/43 & 27.7 & 16 & 62 & 3.1 & 109 & 135 \\
\hline 45R100BF0.5/20 & 27.2 & 14 & 61 & 2.3 & 56 & 101 \\
\hline 45R100F1/20 & 27.7 & 16 & 62 & 1.9 & 30 & 84 \\
\hline 45R100F1.5/20 & 27.3 & 14 & 61 & 2.3 & 56 & 101 \\
\hline 45R100F $2 / 20$ & 27.5 & 15 & 61 & 2.4 & 60 & 104 \\
\hline 45R100F3/20 & 25.7 & 8 & 57 & 2.6 & 74 & 113 \\
\hline 60R0BF0 & 52.7 & - & - & 2.5 & - & - \\
\hline 60R100BF0 & 22.1 & - & - & 1.5 & - & - \\
\hline 60R100BF0.5/43 & 27.5 & 25 & 52 & 2.2 & 45 & 89 \\
\hline 60R100F1/43 & 30.8 & 39 & 58 & 3.3 & 116 & 132 \\
\hline 60R100BF0.5/20 & 24.5 & 11 & 46 & 1.7 & 13 & 69 \\
\hline 60R100F1/20 & 25.3 & 14 & 48 & 1.6 & 8 & 66 \\
\hline 60R100F1.5/20 & 29.1 & 32 & 55 & 2.4 & 58 & 97 \\
\hline 60R100F $2 / 20$ & 29.3 & 33 & 56 & 2.5 & 61 & 99 \\
\hline 60R100F3/20 & 26.9 & 22 & 51 & 2.9 & 89 & 115 \\
\hline
\end{tabular}

For $45 \mathrm{MPa}$-concrete, the addition of up to 1 and 3\% volume fractions of 43 and $20 \mathrm{~mm}$ BF resulted in up to $16 \%$ improvement in compressive strength compared to plain concrete made with $100 \%$ RCA. In terms of retaining the compressive strength of the control mix, incorporating $43 \mathrm{~mm}$ and $20 \mathrm{~mm}$-long BF at volume fractions within 1 and $3 \%$ could retain $62 \%$. The results indicate that similar strength improvement and retention could be achieved using either the 20 or $43 \mathrm{~mm}$ basalt fibers.

Considering $60 \mathrm{MPa}$-concrete, the addition of 0.5 and $1 \%$ volume fractions of $43 \mathrm{~mm}$ BF resulted in 25 and $39 \%$ improvement in compressive strength in comparison with plain RCA-based concrete. An increase from 11 to $33 \%$ in strength was noted when basalt fiber volume fraction increased from 0.5 to $3 \%$. The highest retention of compressive strength for 20 and $43 \mathrm{~mm}$ basalt fiber-reinforced concrete was 58 and 56\% with 3 and $1 \%$ volume fractions. While both basalt fiber types 
could attain similar improvement and retention of strength compared to the control mix, there effectiveness was superior at lower concrete strength of $30 \mathrm{MPa}$.

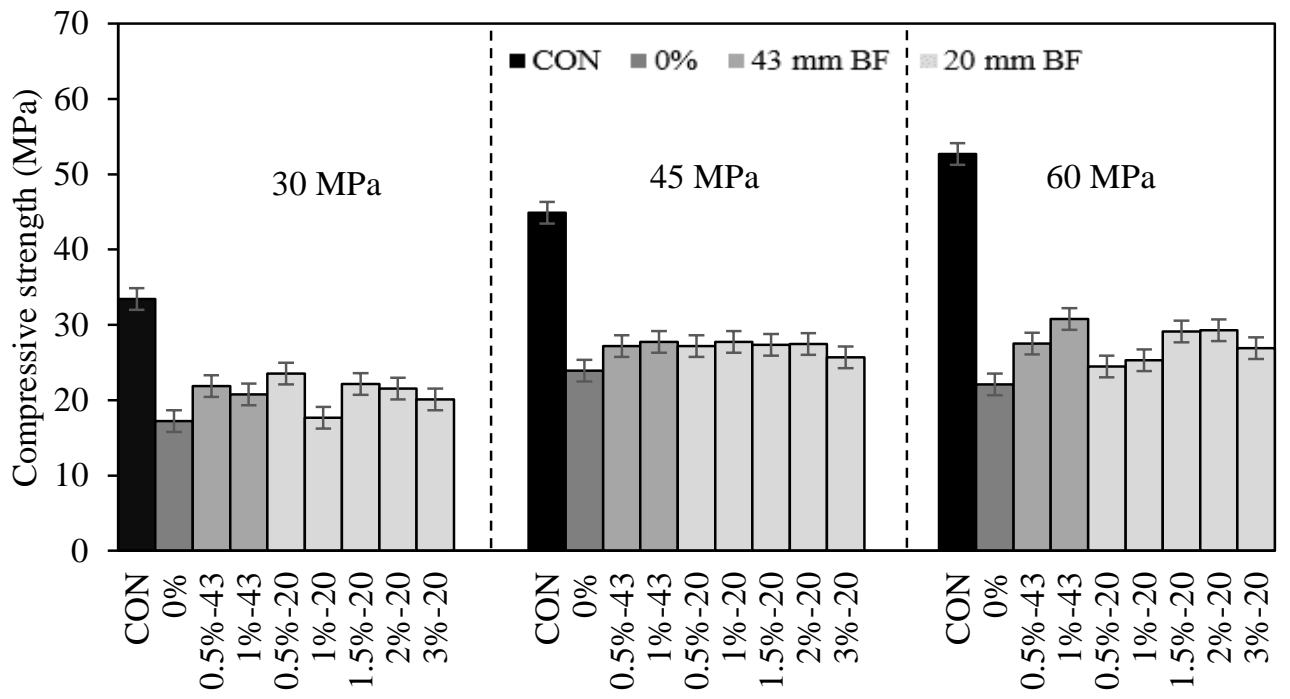

Fig. 3: Compressive strength of concrete mixes with different design strength, fiber lengths, and fiber volume fractions

\subsection{Splitting Tensile Strength}

The 7-day splitting tensile strength of concrete made with different proportions of RCA and basalt fibers is shown in Fig. 4. Triplicate specimens were tested for each mix to obtain an average. The splitting tensile strength of 30, 45, and $60 \mathrm{MPa}$ control mixes was 1.7, 2.3, and $2.5 \mathrm{MPa}$, respectively. The replacement of NA by $100 \%$ RCA decreased the respective control splitting tensile strength by 24,35 , and $40 \%$. Compared to the results of 7-day compressive strength, it is obvious that the replacement of NA by RCA has a less detrimental effect.

The addition of basalt fibers in concrete mixes with 100\% RCA improved splitting tensile strength significantly in comparison to the control mixes, as indicated in Table 2. For $30 \mathrm{MPa}$-concrete, the splitting tensile strength increased by 45 and $86 \%$ when 0.5 and $1 \%$ volume fractions of $43 \mathrm{~mm}$-long basalt fibers were added to RCA-based concrete. In comparison, $0.5,1,1.5,2,3 \%$ volume fractions of $20 \mathrm{~mm}$ basalt fiber resulted in 36, 25, 42, 30, and $48 \%$ respective increase compared to plain concrete made with 100\% RCA. As for the retention level, 20 and $43 \mathrm{~mm}$ fiber addition at volume fractions up to 1 and $3 \%$ resulted in retaining 147 and $117 \%$ of the splitting tensile strength of the control mix. Clearly, both fiber types are effective at increasing the splitting tensile strength to the extent that a stronger concrete than the control was produced. Nevertheless, it is worth noting that $43 \mathrm{~mm}$ basalt fiber-reinforced RCA concrete showed superior performance to $20 \mathrm{~mm}$ counterparts.

For $45 \mathrm{MPa}$-concrete, the addition of up to 1 and 3\% volume fractions of 43 and $20 \mathrm{~mm}$ basalt fibers resulted in up to 109 and $74 \%$ enhancement in splitting tensile strength compared to the plain RCA concrete. With reference to the control mix, the retention level for these volume fractions of the two types of basalt fibers was 135 and $113 \%$. As for 60 MPa-concrete, the splitting tensile strength increased by 45 and $116 \%$ upon adding 0.5 and $1 \%$ volume fractions of 43 $\mathrm{mm}$ BF in comparison to the plain RCA concrete mix. These values denote a retention of 89 and $132 \%$ of the splitting tensile strength of the control mix. On the other hand, the addition of $20 \mathrm{~mm} \mathrm{BF}$ at volume fraction of $0.5,1,1.5,2$, and $3 \%$ increased the splitting tensile strength by $13,8,58,61$, and $89 \%$, respectively, representing a strength retention of $69,66,97,99$, and $115 \%$ of that of the control mix. Similar to the 30 -MPa concrete mix, $43 \mathrm{~mm}$ basalt fiber-reinforced RCA concrete presented higher splitting tensile strength enhancement and retention than $20 \mathrm{~mm}$ equivalents. However, the addition of $43 \mathrm{~mm}$-long basalt fibers to concrete mixes is more effective with higher design compressive strengths. 


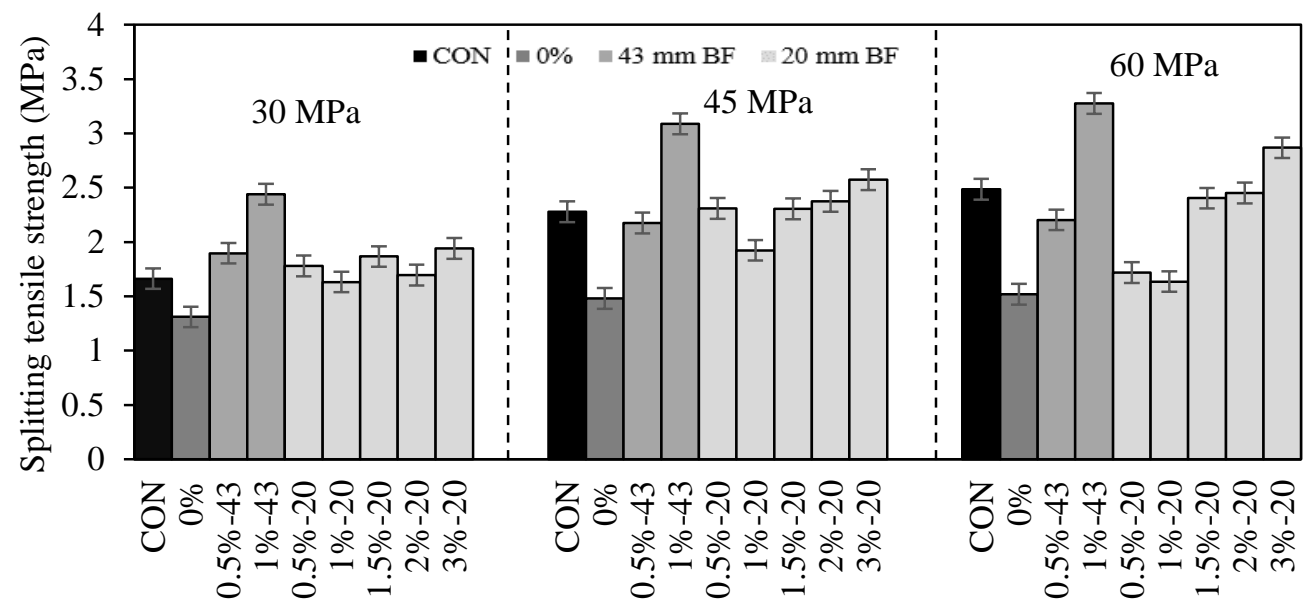

Fig. 4: Splitting tensile strength of concrete mixes with different design strength, fiber lengths, and fiber volume fractions

\section{Conclusions}

This paper demonstrates the combined effect of basalt fibers and recycled concrete aggregates on performance of concrete mixes made with desert dune sand. The experimental investigation was performed on cylinder and cube specimens to determine workability, compressive strength, and splitting tensile strength. The following conclusions can be drawn:

(i) The replacement of NA by $100 \%$ RCA had a negligible effect on the concrete workability. The addition of basalt fibers decreased slump, especially when $43 \mathrm{~mm}$-long fibers and/or high volume fractions were employed.

(ii) Significant reduction in 7-day compressive strength was noted upon replacement of $100 \%$ NA by RCA. Higher reduction percentages were associated with concrete having higher design strength. The incorporation of 20 and 43 mm-long basalt fibers resulted in similar improvement of compressive strength for $100 \%$ RCA concrete with design strength of 45 and $60 \mathrm{MPa}$. Yet, the shorter fibers were relatively superior to longer ones when both were incorporated at a fiber volume fraction of $0.5 \%$ in concrete with lower design strength $(30 \mathrm{MPa})$. This was, however, not evident when the fiber volume fraction was $1 \%$. In terms of strength retention, fibers were general more effective at retaining the design strength of $30 \mathrm{MPa}$ control mixes upon replacing NA with RCA.

(iii) The 7-day splitting tensile strength of concrete increased with an increase in basalt fiber volume fraction for both lengths, i.e., 20 and $43 \mathrm{~mm}$. The splitting tensile strengths of basalt fiber-reinforced concrete mixes made with $100 \%$ RCA were higher than that of the RCA-based control mix and, in most cases, even higher than that of the NA-based control mix. Among the two fiber lengths, the longer $(43 \mathrm{~mm})$ led to a higher increase in splitting tensile strength. They were especially effective when incorporated into concrete with high design strength (60 MPa).

\section{Acknowledgements}

The authors gratefully acknowledge the financial support provided by UAE University under grants number 31 N398 and $31 \mathrm{~N} 324$.

\section{References}

[1] C. R. Gagg, "Cement and concrete as an engineering material: An historic appraisal and case study analysis," Eng. Fail. Anal., vol. 40, pp. 114-140, May 2014, doi: 10.1016/j.engfailanal.2014.02.004.

[2] N. Bandow, S. Gartiser, O. Ilvonen, and U. Schoknecht, "Evaluation of the impact of construction products on the environment by leaching of possibly hazardous substances," Environ. Sci. Eur., vol. 30, no. 1, p. 14, May 2018, doi: 10.1186/s12302-018-0144-2.

[3] P. Thongkamsuk, K. Sudasna, and T. Tondee, "Waste generated in high-rise buildings construction: A current situation in Thailand," Energy Procedia, vol. 138, pp. 411-416, Oct. 2017, doi: 10.1016/j.egypro.2017.10.186. 
[4] F. U. Ahmed Shaikh, P. Nath, A. Hosan, M. John, and W. K. Biswas, "Sustainability assessment of recycled aggregates concrete mixes containing industrial by-products," Mater. Today Sustain., vol. 5, p. 100013, Sep. 2019, doi: 10.1016/j.mtsust.2019.100013.

[5] R. K. Dhir, K. A. Paine, and S. O'Leary, "Use of Recycled Concrete Aggregate in Concrete Pavement Construction: A Case Study," in Sustainable Waste Management, 0 vols., Thomas Telford Publishing, 2003, pp. 373-382.

[6] J. Junak and A. Sicakova, "Effect of Surface Modifications of Recycled Concrete Aggregate on Concrete Properties," Buildings, vol. 8, no. 1, p. 2, Jan. 2018, doi: 10.3390/buildings8010002.

[7] V. Spaeth and A. Djerbi Tegguer, "Improvement of recycled concrete aggregate properties by polymer treatments," Int. J. Sustain. Built Environ., vol. 2, no. 2, pp. 143-152, Dec. 2013, doi: 10.1016/j.ijsbe.2014.03.003.

[8] N. Kachouh, H. El-Hassan, and T. El-Maaddawy, "The use of steel fibers to enhance the performance of concrete made with recycled aggregate," in: Fifth International Conference on Sustainable Construction Materials and Technologies, 2019, pp. 76-86, doi: 10.18552/2019/IDSCMT5012.

[9] N. Kachouh, H. El-Hassan, and T. El-Maaddawy, "Effect of steel fibers on the performance of concrete made with recycled concrete aggregates and dune sand," Constr. Build. Mater., vol. 213, pp. 348-359, Jul. 2019, doi: 10.1016/j.conbuildmat.2019.04.087.

[10]N. Kachouh, H. El-Hassan, and T. El-Maaddawy, "Influence of steel fibers on the flexural performance of concrete incorporating recycled concrete aggregates and dune sand," J. Sust. Cem. Based Mater., published online, pp.1-28, Aug. 2020, doi: 10.1080/21650373.2020.1809546.

[11] S.-E. Fang, H.-S. Hong, and P.-H. Zhang, "Mechanical Property Tests and Strength Formulas of Basalt Fiber Reinforced Recycled Aggregate Concrete," Mater., vol. 11, no. 10, Sep. 2018, doi: 10.3390/ma11101851.

[12]Y. Wang, P. Hughes, H. Niu, and Y. Fan, "A new method to improve the properties of recycled aggregate concrete: Composite addition of basalt fiber and nano-silica," J. Clean. Prod., vol. 236, p. 117602, Nov. 2019, doi: 10.1016/j.jclepro.2019.07.077.

[13]BS EN 206:2013+A1:2016, "Concrete. Specification, performance, production and conformity", British Standards Institution, 2016.

[14]ASTM C143 / C143M-15a, "Standard Test Method for Slump of Hydraulic-Cement Concrete", ASTM International, West Conshohocken, PA, 2015.

[15]BS EN 12390-3:2002, "Testing hardened concrete. Compressive strength of test specimens", British Standards Institution, 2002.

[16]ASTM C496 / C496M-17, Standard Test Method for Splitting Tensile Strength of Cylindrical Concrete Specimens, ASTM International, West Conshohocken, PA, 2017.

[17] Safiuddin, U. J. Alengaram, A. Salam, M. Z. Jumaat, F. F. Jaafar, and H. B. Saad, "Properties of high-workability concrete with recycled concrete aggregate," Mater. Res., vol. 14, no. 2, pp. 248-255, 2011, doi: 10.1590/S151614392011005000039. 